\title{
New composite material based on heavy concrete reinforced by basalt-boron fiber for radioactive waste management
}

\author{
Iryna Romanenko ${ }^{1}$, Maryna Holiuk ${ }^{1}$, Pavlo Kutsyn ${ }^{1}$, Iryna Kutsyna ${ }^{1}$, Hennadii Odynokin ${ }^{1}$, Anatolii Nosovskyi ${ }^{1}$, \\ Vitalii Pastsuk ${ }^{2}$, Madis Kiisk ${ }^{2}$, Alex Biland ${ }^{3}$, Yurii Chuvashov ${ }^{4}$, and Volodymyr Gulik ${ }^{1,2, *}$ \\ ${ }^{1}$ Nuclear facility safety department, Institute for Safety Problems of Nuclear Power Plants, Lysogirska 12, 03142 Kyiv, Ukraine \\ 2 Institute of Physics, University of Tartu, W. Ostwaldi 1, 50411 Tartu, Estonia \\ ${ }^{3}$ US Basalt Corp., Richmond, TX 77407, USA \\ ${ }^{4}$ Institute for Problems in Materials Science, Krzhizhanovsky 3, 03142 Kyiv, Ukraine
}

Received: 15 August 2019 / Accepted: 2 September 2019

\begin{abstract}
A new composite material with neutron radiation shielding properties is presented. This fiber reinforced concrete material incorporates basalt-boron fiber, with different concentrations of boron oxide in fiber, and is applicable to nuclear energy and nuclear waste management. The methodology for production of boron oxide $\left(\mathrm{B}_{2} \mathrm{O}_{3}\right)$ infused basalt fiber has been developed. First experimental samples of basalt boron fiber containing $6 \%$ of $\mathrm{B}_{2} \mathrm{O}_{3}$ and $12 \% \mathrm{~B}_{2} \mathrm{O}_{3}$ have been produced in laboratory conditions. The concrete samples reinforced by two types of basalt-boron fiber with different dosages have been prepared for neutron experiment. The neutron experimental investigations on radiation shielding properties of concrete reinforced by basalt-boron fiber have been performed by means of $\mathrm{Pu}$-Be neutron source. The prepared samples have been tested in the course of several series of tests. It is shown that basalt-boron fibers in concrete improve neutron radiation shielding properties for neutrons with different energies, but it appears to be most effective when it comes to thermal neutrons.
\end{abstract}

\section{Introduction}

For safe operation of various sources of radioactivity, it is necessary to have reliable radiation protection. To date, there are many different types of radiation sources in the world, such as conventional fission reactors, fusion neutron sources, D-D and D-T neutron generators, plasma focus devices used as neutron sources and many gamma sources $[1,2]$. These radiation sources are used for industrial, scientific and medical purposes.

At the moment, there are different types of radiation shielding. The most widespread is heavy concrete with various additives [3-12]. Such heavy concrete should have radiation shielding properties, both against neutron and gamma irradiation. For example, in order to protect against gamma radiation, we need to use materials with large values of the atomic number Z [13]. As a result, for protection against gamma radiation, fillers are used most widely, among them such natural minerals as barite containing a lot of barium, magnetite, which consists of titanium and iron, and serpentinite. For VVER reactors,

\footnotetext{
* e-mail: volodymyr.gulik@gmail.com
}

heavy concrete with serpentinite is used as biological shielding [14]. Serpentinite contains such heavy elements as iron and magnesium.

In addition to heavy minerals, concrete should contain elements that are well scattering and absorb neutrons. By default, the concrete contains a large amount of hydrogen, on the nuclei of which effective neutron scattering is observed.

In this paper, the authors suggest a new type of composite material based on heavy concrete reinforced by improved basalt-boron fiber (BBF), in which the boron oxide is added during the production process.

\section{Basalt-boron fiber}

The proposal to add a basalt fiber (BF) containing boron is based on the fact that there is enough hydrogen in the concrete to slow down fast neutrons, and if we add a material with a large neutron absorption cross section (for example, B-10), then it can become very effective material with neutron radiation shielding properties [14].

Basalt fiber is produced similarly to glass fiber. The BF production contains several stages: the preparation of the basalt rock, the melting, the formation of fiber, the drying of the fiber, cutting the fiber and obtaining final products [15]. 


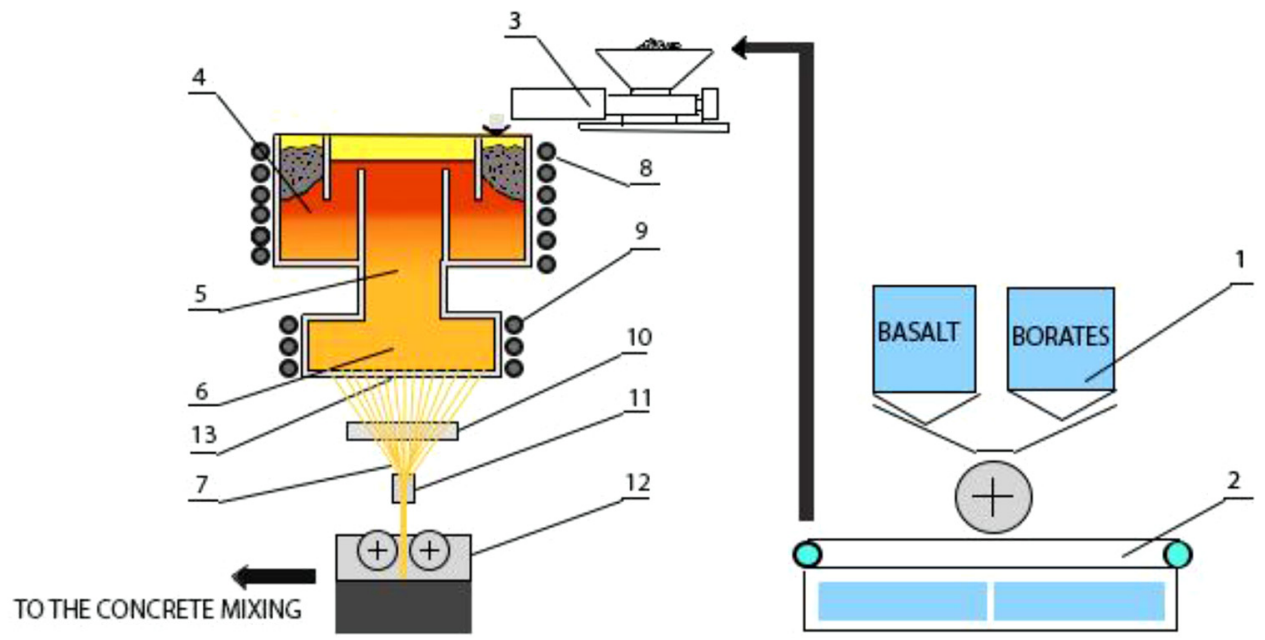

Fig. 1. Scheme of the process for BBF production. (1) Metering \& mixing equipment (batch preparation). (2) Conveying equipment. (3) Batch charger. (4) Melting chamber. (5) Conditioning chamber. (6) Fiber forming chamber. (7) Fiber's strand. (8) Induction coil of melting chamber. (9) Induction coil of fiber forming chamber. (10) Sizing applicator. (11) Gathering shoe. (12) Direct chopper. (13) Fiber drawing plate [13].

Table 1. The chemical composition of BBF type BasBor6.

\begin{tabular}{lllllllll}
\hline Main constituents & $\mathrm{B}_{2} \mathrm{O}_{3}$ & $\mathrm{Na} 2$ & $\mathrm{MgO}$ & $\mathrm{Al}_{2} \mathrm{O}_{3}$ & $\mathrm{SiO}_{2}$ & $\mathrm{P}_{2} \mathrm{O}_{5}$ & $\mathrm{SO}_{3}$ & $\mathrm{Cl}$ \\
$\%$ & 6.2 & 1.809 & 5.93 & 13.888 & 50.40 & 0.125 & 0.015 & 0.010 \\
Main constituents & $\mathrm{K} 2 \mathrm{O}$ & $\mathrm{CaO}$ & $\mathrm{TiO}_{2}$ & $\mathrm{~V}_{2} \mathrm{O}_{5}$ & $\mathrm{MnO}$ & $\mathrm{Fe}_{2} \mathrm{O}_{3}$ & $\mathrm{Co}_{2} \mathrm{O}_{3}$ & $\mathrm{NiO}$ \\
$\%$ & 1.439 & 8.040 & 1.134 & 0.08 & 0.164 & 10.590 & 0.0033 & 0.002 \\
Main constituents & $\mathrm{CuO}$ & $\mathrm{ZnO}$ & $\mathrm{Ga}_{2} \mathrm{O}_{3}$ & $\mathrm{Rb}_{2} \mathrm{O}$ & $\mathrm{SrO}$ & $\mathrm{Y}_{2} \mathrm{O}_{3}$ & $\mathrm{ZrO}_{2}$ & $\mathrm{BaO}$ \\
$\%$ & 0.003 & 0.014 & 0.002 & 0.0067 & 0.0349 & 0.006 & 0.0032 & 0.03 \\
\hline
\end{tabular}

Table 2. The chemical composition of BBF type BasBor12.

\begin{tabular}{lllllllll}
\hline Main constituents & $\mathrm{B}_{2} \mathrm{O}_{3}$ & $\mathrm{Na}_{2} \mathrm{O}$ & $\mathrm{MgO}$ & $\mathrm{Al}_{2} \mathrm{O}_{3}$ & $\mathrm{SiO}_{2}$ & $\mathrm{P}_{2} \mathrm{O}_{5}$ & $\mathrm{SO}_{3}$ & $\mathrm{Cl}$ \\
$\%$ & 11.7 & 1.715 & 5.66 & 13.120 & 47.64 & 0.117 & 0.010 & 0.008 \\
Main constituents & $\mathrm{K}_{2} \mathrm{O}$ & $\mathrm{CaO}$ & $\mathrm{TiO}_{2}$ & $\mathrm{~V}_{2} \mathrm{O}_{5}$ & $\mathrm{MnO}$ & $\mathrm{Fe}_{2} \mathrm{O}_{3}$ & $\mathrm{Co}_{2} \mathrm{O}_{3}$ & $\mathrm{NiO}$ \\
$\%$ & 1.313 & 7.421 & 1.044 & 0.051 & 0.149 & 9.688 & 0.0028 & 0.003 \\
Main constituents & $\mathrm{CuO}$ & $\mathrm{ZnO}$ & $\mathrm{Ga}_{2} \mathrm{O}_{3}$ & $\mathrm{Rb}_{2} \mathrm{O}$ & $\mathrm{SrO}$ & $\mathrm{Y}_{2} \mathrm{O}_{3}$ & $\mathrm{ZrO}_{2}$ & $\mathrm{BaO}$ \\
$\%$ & 0.0028 & 0.012 & 0.003 & 0.0061 & 0.0313 & 0.005 & 0.0029 & 0.03 \\
\hline
\end{tabular}

However, the process of BBF production is easier than the production of glass fiber: it does not require a complicated and expensive process of preparation of the charge, but requires only one supply line of crushed basalt rocks in the furnace for melting. The basalt breed is first crushed, then washed, dried and loaded into containers attached to the heater, which mixes the basalt to the melting bath in gas ovens (see Fig. 1).

A number of studies have shown that concrete reinforced with $\mathrm{BF}$ has high chemical and corrosion resistance, durability, resistance to abrasion, and frost resistance $[1,13-17]$. Since the specific density of the BF is approximately the same as that of the main components of the concrete, it is evenly distributed over the entire volume of concrete in the form of steel and other types of polymer fiber.

The first experimental samples of BBF were prepared in Institute for Problems in Materials Science in Ukraine for two different types of basalt fibers infused with boron as reinforcing material. The first type of $\mathrm{BBF}$, hereinafter referred to as BasBor6, contains $6 \%$ of $\mathrm{B}_{2} \mathrm{O}_{3}$, of which $19.8 \%$ B-10 and $80.2 \%$ B- 11 . The second type of BBF, represented in the text as BasBor 12 , contains $12 \%$ of $\mathrm{B}_{2} \mathrm{O}_{3}$, of which $19.8 \% \mathrm{~B}-10$ and $80.2 \% \mathrm{~B}-11$. The chemical composition of the $\mathrm{BBF}$ with the infusion of boron BasBor6 is displayed on Table 1. The chemical composition of the BBF with the infusion of boron BasBor12 is displayed in Table 2.

\section{Radiation shielding properties experiment for $\mathrm{Pu}$-Be neutron source}

\subsection{Description of experiment}

For measurements a plutonium-beryllium neutron source, (ИБН-12) was used, creating a flux of fast neutrons with 
Table 3. The main technical characteristics of neutron source.

\begin{tabular}{|c|c|c|c|c|c|}
\hline \multirow[t]{2}{*}{ Source type } & \multicolumn{2}{|c|}{ Source dimensions (active part), $\mathrm{mm}$} & \multirow[t]{2}{*}{$\begin{array}{l}\text { Neutron intensity, } \\
\quad \text { neutrons s }{ }^{-1} \\
\end{array}$} & \multicolumn{2}{|c|}{$\begin{array}{c}\text { Maximum activity } \\
\mathrm{Pu}-239 \text { at source }\end{array}$} \\
\hline & $\begin{array}{l}\text { Diameter, } \\
D(\mathrm{~d})\end{array}$ & $\begin{array}{l}\text { Height (Length) } \\
H(h),(\mathrm{L})\end{array}$ & & $\mathrm{Bq}$ & $\mathrm{Ci}$ \\
\hline ИБН-12 & $54(46)$ & $64(46)$ & $(5.0 \pm 1.0) \times 10^{7}$ & $1.3 \times 10^{12}$ & 35 \\
\hline
\end{tabular}

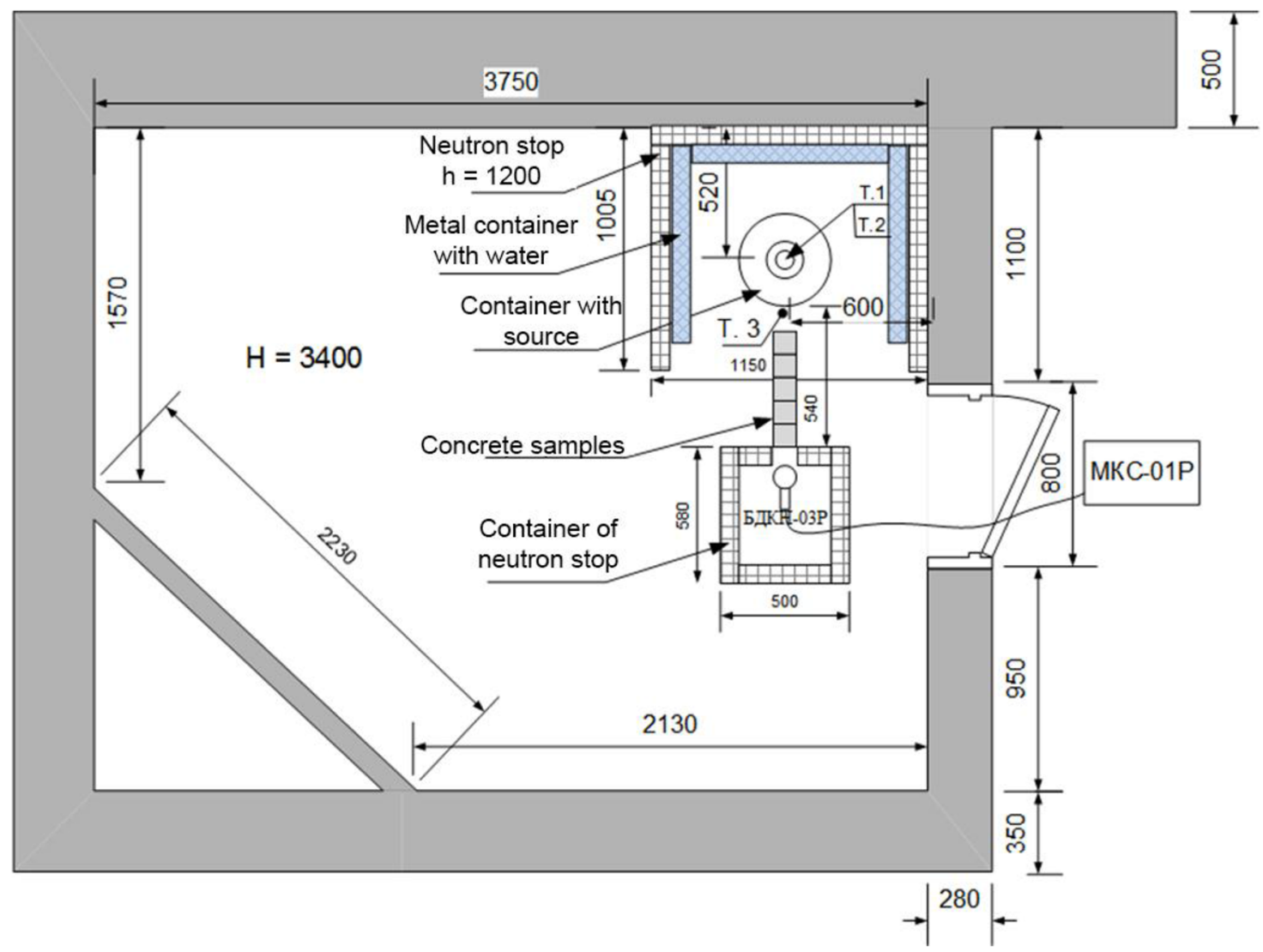

Fig. 2. Layout of the room and equipment placement during measurements.

isotropic distribution and intensity $5 \times 10^{7}$ neutrons $\mathrm{s}^{-1}$. Table 3 shows its main technical characteristics.

Measurements of the neutron flux were carried out with a radiometer-dosimeter $\mathrm{MKC}-01 \mathrm{P}$ with a detection unit БДКН-03Р. The apparatus measurement error of the MKC-01P when measuring the neutron flux does not exceed $20 \%$. Measurements of neutron flux were carried out in two types of the neutron energy spectrum:

- for "thermal" neutrons;

- for intermediate and fast neutrons (with cadmium attachment to the detecting unit).

The measurements were carried out for two conditions of irradiation of the samples, in different geometries:

- concrete samples are placed in an isotropic neutron field from a $\mathrm{Pu}$-Be neutron source ("simple" neutron experiment);
- measurements with geometry, allowing to take into account the reflected and scattered neutrons ("complex" neutron experiment).

During the measurements, the neutron source ИБН-12 was in the transport container. The transport container is a metal container with a central tube into which the source is installed. The inner space of the container is filled with paraffin. For personnel protection, a container with a source from three sides was surrounded by panels of "neutron stops" of type TP12-41-MMS 065/73 and metal tanks with water. "Neutron stops" are blocks of polyethylene with boron content and are effective neutron absorbers. The thickness of the neutron-stop panels is $70 \mathrm{~mm}$. Water tank thickness $150 \mathrm{~mm}$.

The floor plan and layout of equipment is shown in Figure 2, and Figure 3 shows a front view of the source and the overall dimensions of the equipment. 


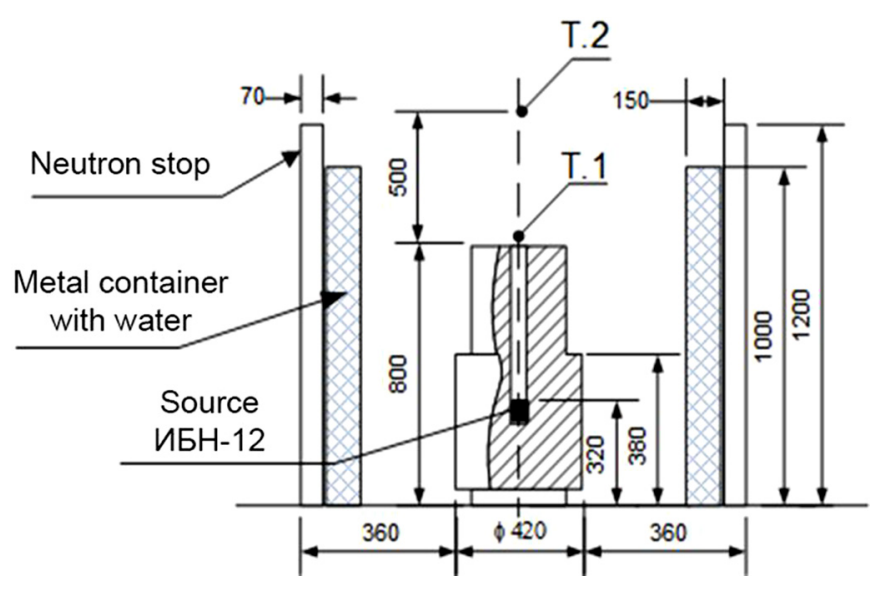

Fig. 3. Frontal view and overall dimensions of the container with a neutron source.

As mentioned above, this study investigates two different types of basalt fibers infused with boron as reinforcing material (BasBor6 and BasBor12). There are 5 types of concrete mixtures in the neutron experiment conducted, all of them with same type of cement, CEM I $42.5 \mathrm{R}$, same water-to-cement ratio and same river sand as fine aggregate. The density of concrete was $2.33 \mathrm{~g} / \mathrm{cm}^{3}$. All in all, there are five main types of concrete mixtures in this study and they are noted throughout the paper as follows: $\mathbf{R}$ - plain concrete without BBF; A - concrete with BasBor6 dosage: $5 \mathrm{~kg} / \mathrm{m}^{3} ; \mathbf{B}$ - concrete with BasBor6 dosage: $20 \mathrm{~kg} / \mathrm{m}^{3} ; \mathbf{C}$ - concrete with BasBor12 dosage: $5 \mathrm{~kg} / \mathrm{m}^{3} ; \mathbf{D}$ - concrete with BasBor12 dosage: $30 \mathrm{~kg} / \mathrm{m}^{3}$. Concrete samples have dimensions: $10 \mathrm{~cm} \times 10 \mathrm{~cm} \times 10 \mathrm{~cm}$.

\section{2 "Simple" experiment}

The scheme of measurement of geometry in a "simple" experiment is shown in Figure 4. The detecting unit was located along the axis and at the height of the source in the containers. The distance between the detecting unit and the front wall of the container is $\mathrm{L}=500 \mathrm{~mm}$.

Ten measurements were conducted without samples of concrete. The measurements were carried out for thermal (see Fig. 5) as well as intermediate and fast neutrons (using a detection unit with an installed cadmium packing (see Fig. 6)).

Between the detecting unit and the source, one to five concrete samples from each set were sequentially installed. Ten measurements were conducted for each configuration and set of samples. The measurements were carried out for thermal as well as intermediate and fast neutrons (a detection unit with an installed cadmium packing). All experimental and simulations results will be presented in next journal paper which is currently being prepared.

\section{3 “Complex" experiment}

A diagram of the measurement geometry in a "complex" experiment is shown in Figure 7.

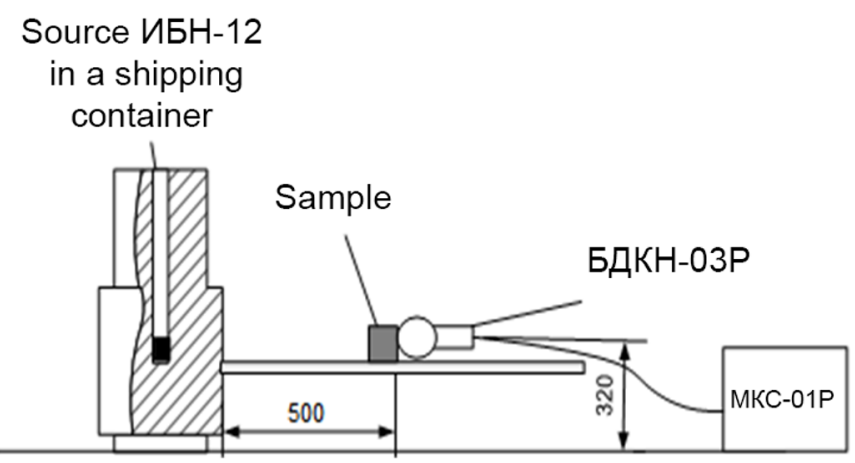

Fig. 4. Schematic representation of measurement geometry in a "simple" experiment.

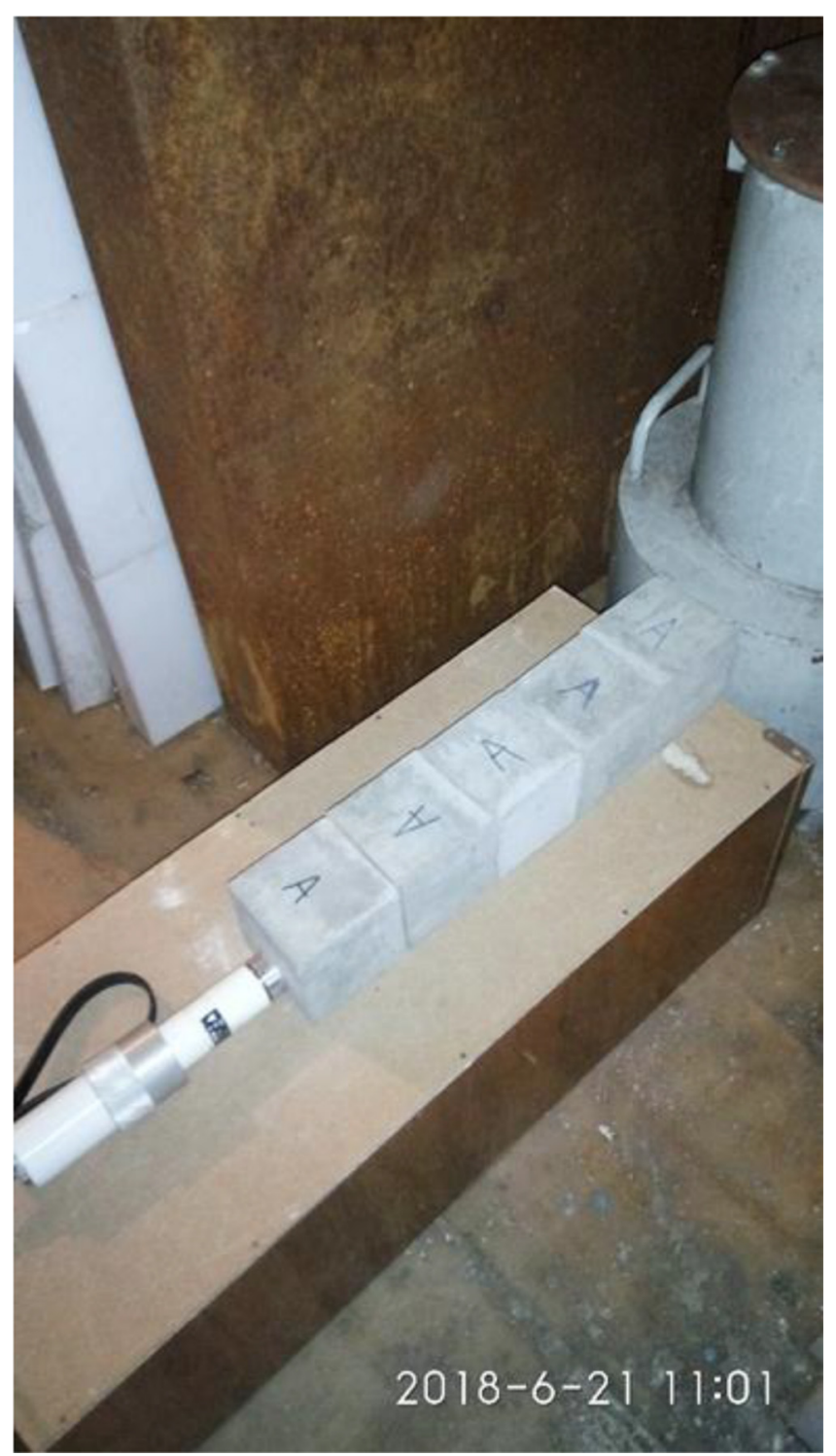

Fig. 5. The measurements for thermal neutrons.

For measurements, a container was assembled from "neutron stops". The container is a box with dimensions of $580 \times 500 \times 300 \mathrm{~mm}$ closed on all sides, with wall thickness 


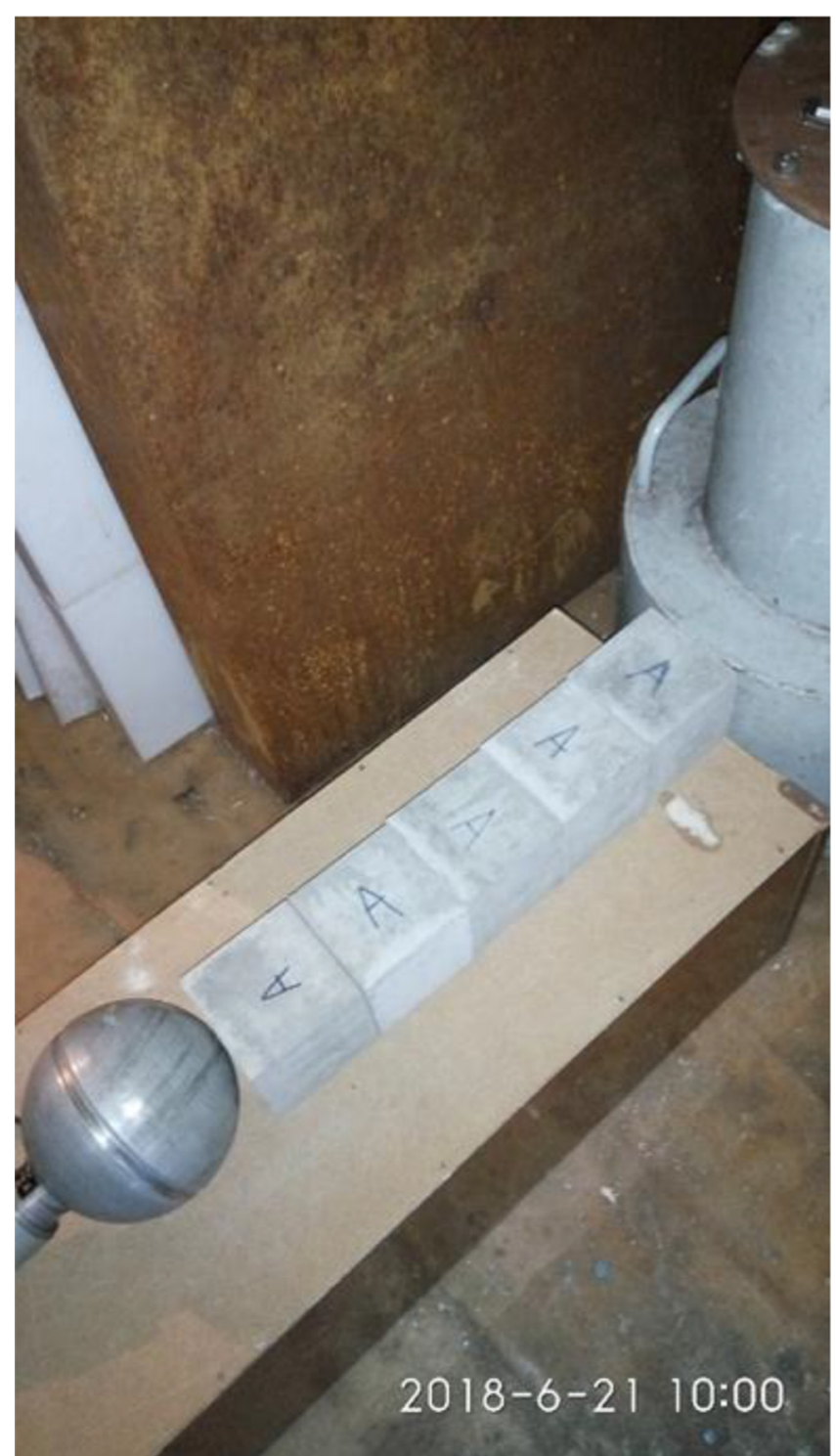

Fig. 6. The measurements for intermediate and fast neutrons.

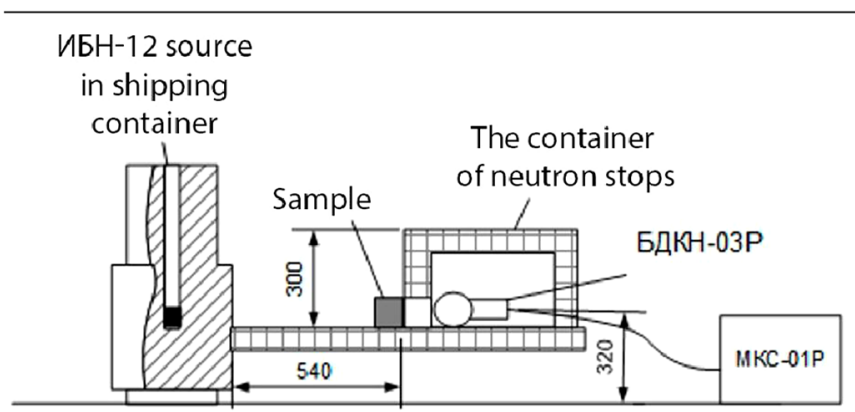

Fig. 7. Schematic representation of the measurement geometry in a "complex" experiment.

$70 \mathrm{~mm}$. In one of the walls of the container, a rectangular opening with a section equal to the section of the samples is made. A detection unit was installed inside the container opposite the opening. This measurement geometry allows shielding from neutrons reflected from the walls of the room and equipment, and taking into account their contribution to the measurement results of neutron flux.

The hole in the container was closed with a stopper made of neutron stops and 10 measurements of $\varphi_{\phi}-$ background neutron flux were performed. The measurements were carried out for thermal as well as intermediate and fast neutrons (a detection unit with an installed cadmium packing).

Ten measurements of neutron flux $\varphi_{0}$ were conducted without samples of concrete. The measurements were carried out for thermal as well as intermediate and fast neutrons (a detection unit with an installed cadmium packing).

Opposite the opening between the detection unit and the source, one to five concrete samples from each set were sequentially installed. Ten measurements of neutron flux were then conducted for each configuration and set of samples. The measurements were carried out for thermal as well as intermediate and fast neutrons (a detection unit with an installed cadmium packing).

Based on the results obtained of neutron flux density measurements, the mean values, the standard deviation and the relative statistical error of each measurement by formulas (1)-(3) were calculated.

$$
\begin{gathered}
\bar{\varphi}=\frac{\sum_{i=1}^{i=n} \varphi_{i}}{n}, \\
\sigma=\sqrt{\frac{\sum_{i=1}^{i=n} \varphi_{i}-\bar{\varphi}}{n-1},} \\
\delta=2 \times \frac{\sigma}{\bar{\varphi}} \times \sqrt{n} \times 100 \%,
\end{gathered}
$$

where, $\varphi i$ - measured values of neutron flux, neutron/ $\left(\mathrm{cm}^{2} \mathrm{sec}\right) ; \bar{\varphi}-$ the average value of neutron flux, neutron/ $\left(\mathrm{cm}^{2} \mathrm{sec}\right) ; n=10$ is the number of measurements; $\sigma-$ standard deviation, neutron $/\left(\mathrm{cm}^{2} \mathrm{sec}\right) ; \delta$ is the limit of the relative statistical error, percentage.

The results of measurements and calculations in the "complex" experiment for all series of measurements are given in Tables 4 and 5 . The numbers 1-5 mean that: 1 - one concrete sample between source and detector; 2 - two concrete samples between source and detector; 3 three concrete samples between source and detector; 4 four concrete samples between source and detector; 5 - five concrete samples between source and detector.

It can be seen from Table 4 that there is a slight increase of neutron radiation shielding properties (up to $5 \%$ ) in the case of low concentrations of $\mathrm{BBF}$ in concrete (A and $\mathrm{C}$ types of concrete samples), but considerable increase of neutron radiation shielding properties (up to 13\%) with the addition of higher concentration of BBF in concrete (B and D types of concrete samples) for intermediate and fast neutrons. It can also be noted from Table 5 that a similar trend can be observed for thermal neutrons, which is a direct result of the increased fraction of neutrons with high absorption cross-section for Boron-10 in the thermal 
Table 4. The neutron-physical characteristics on radiation shielding experiment for intermediate and fast neutrons.

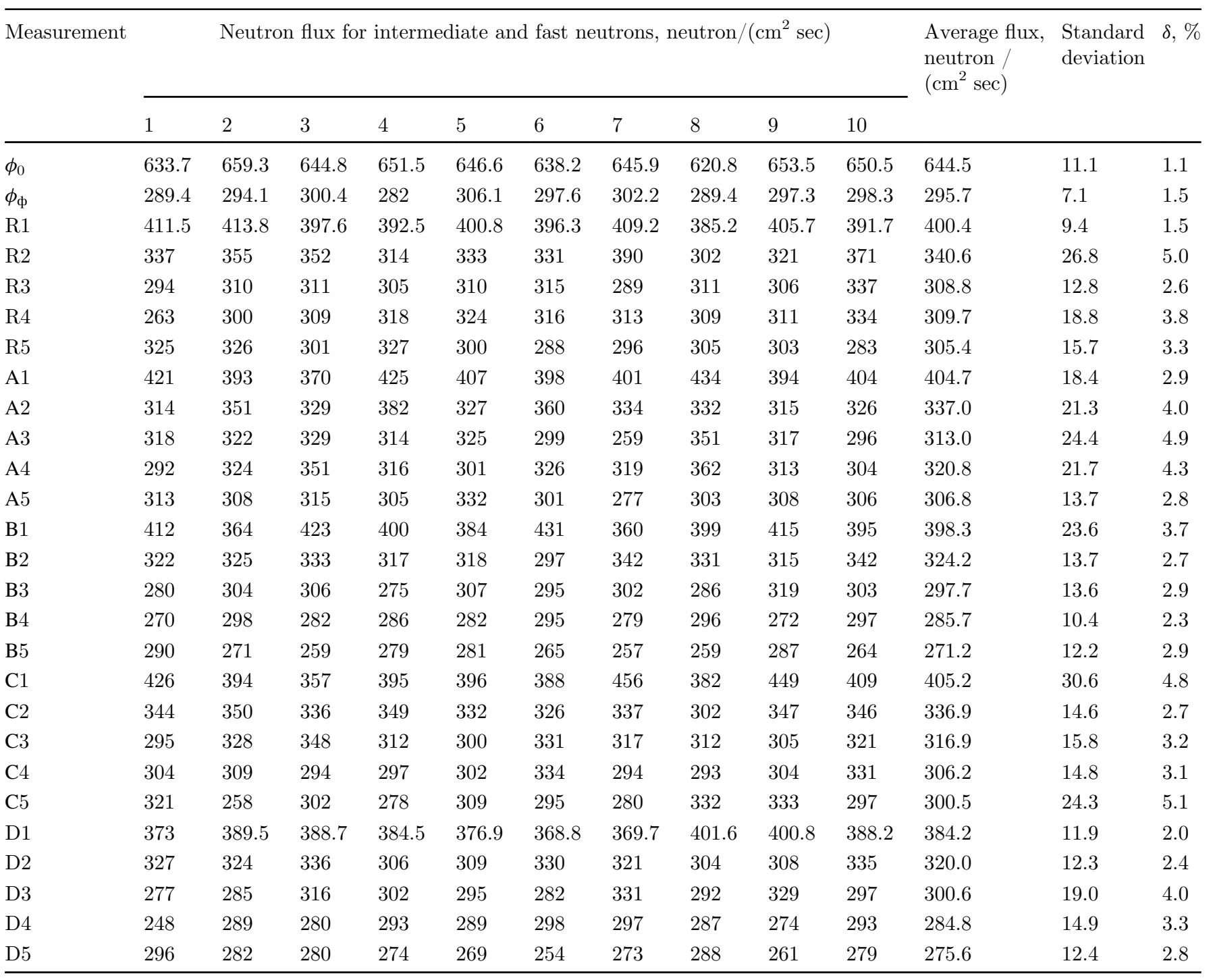

neutron spectrum. Therefore, it could be argued that the use BBF could decrease the thickness of radiation shielding protection at nuclear energy applications.

\section{Conclusions}

In present work, the radiation shielding properties of basalt-boron fiber reinforced concrete are investigated. The samples of basalt fibers infused with boron oxide are prepared for neutron experiment. Two types of basaltboron fiber referred to as BasBor6 (contains $6 \%$ of $\mathrm{B}_{2} \mathrm{O}_{3}$ ) and BasBor12 (contains $12 \%$ of $\mathrm{B}_{2} \mathrm{O}_{3}$ ) are used for preparation of four types of fiber concrete samples. The neutron radiation shielding experiment for concrete samples with different dosages of basalt-boron fiber are conducted with help of $\mathrm{Pu}$-Be neutron source. The experiment includes $\mathrm{Pu}-\mathrm{Be}$ neutron source (ИБН-12), a radiometer-dosimeter MKC-01P with a detection unit БДКН-03P and panels of "neutron stops" of type ТР1241-MMS 065/73.
It is found that the addition of basalt-boron fiber in concrete has effects for fiber dosages $20 \mathrm{~kg} / \mathrm{m}^{3}$ and $30 \mathrm{~kg} / \mathrm{m}^{3}$ in case of thermal and fast neutrons. Obviously, a low dosage of basalt-boron fiber $\left(5 \mathrm{~kg} / \mathrm{m}^{3}\right)$ does not produce a noticeable effect in neutron radiation shielding properties.

The presented experimental results indicate that basalt-boron fiber reinforced concrete has a good potential for use in nuclear energy application and in nuclear waste management. Also, the basalt-boron fiber reinforced concrete is expected to have good mechanical properties including enhanced tensile strength and strong durability, based on its fiber content.

This research was supported by Horizon 2020 ERA-NET Support Programme, Research Grant Agreement No 7.9-3/18/7 ("Development of Boron-Infused Basalt-Fiber Reinforced Concrete for Nuclear and Radioactive Waste Management Applications"). Implementation of activities described in the Roadmap to Fusion during Horizon 2020 through a joint programme of the members of the EUROfusion consortium (2014-2020), Work Package PMI. Also, this research was carried out with the financial support of 
Table 5. The neutron-physical characteristics on radiation shielding experiment for thermal neutrons.

\begin{tabular}{|c|c|c|c|c|c|c|c|c|c|c|c|c|c|}
\hline \multirow[t]{2}{*}{ Measurement } & \multicolumn{10}{|c|}{ Neutron flux for thermal neutrons, neutron $/\left(\mathrm{cm}^{2} \mathrm{sec}\right)$} & \multirow{2}{*}{$\begin{array}{l}\text { Average flux, } \\
\text { neutron/ } \\
\left(\mathrm{cm}^{2} \mathrm{sec}\right)\end{array}$} & \multirow{2}{*}{$\begin{array}{l}\text { Standard } \\
\text { deviation }\end{array}$} & \multirow[t]{2}{*}{$\delta, \%$} \\
\hline & 1 & 2 & 3 & 4 & 5 & 6 & 7 & 8 & 9 & 10 & & & \\
\hline$\varphi_{0}$ & 129.7 & 133 & 132.6 & 134.6 & 126.3 & 133.4 & 132.8 & 129.9 & 129.8 & 128.9 & 131.1 & 2.6 & 1.2 \\
\hline$\varphi \phi$ & 21.6 & 20.8 & 18.5 & 18.6 & 22.7 & 18.1 & 19.1 & 19.3 & 22.6 & 20.2 & 20.2 & 1.7 & 5.4 \\
\hline $\mathrm{R} 1$ & 52 & 49 & 46 & 48 & 50 & 56 & 49 & 45 & 46 & 50 & 49.1 & 3.2 & 4.2 \\
\hline $\mathrm{R} 2$ & 45 & 52 & 48 & 41 & 58 & 51 & 50 & 47 & 52 & 47 & 49.1 & 4.6 & 6.0 \\
\hline R3 & 47 & 45 & 53 & 47 & 48 & 49 & 44 & 53 & 50 & 51 & 48.7 & 3.1 & 4.0 \\
\hline $\mathrm{R} 4$ & 55 & 41 & 43 & 46 & 40 & 46 & 52 & 44 & 54 & 52 & 47.3 & 5.5 & 7.4 \\
\hline $\mathrm{R} 5$ & 49 & 54 & 47 & 43 & 48 & 42 & 47 & 48 & 52 & 50 & 48.0 & 3.7 & 4.8 \\
\hline A1 & 48.8 & 49.3 & 51.3 & 51.8 & 56.8 & 51.5 & 51.6 & 49.9 & 51.3 & 54.1 & 51.6 & 2.3 & 2.9 \\
\hline $\mathrm{A} 2$ & 45.6 & 49.7 & 47 & 49.1 & 46.1 & 46.2 & 44.8 & 48.5 & 50 & 45.7 & 47.3 & 1.9 & 2.5 \\
\hline A3 & 46.5 & 45.8 & 45.7 & 47.1 & 41.5 & 45.6 & 46.3 & 46.9 & 49.3 & 50.2 & 46.5 & 2.3 & 3.2 \\
\hline $\mathrm{A} 4$ & 49.5 & 46.5 & 48.5 & 48.8 & 45.3 & 47.7 & 46.6 & 45.3 & 45.5 & 44.9 & 46.9 & 1.7 & 2.2 \\
\hline A 5 & 44.6 & 44.7 & 45.7 & 46.9 & 50.7 & 42.7 & 46.9 & 44.8 & 45.5 & 42.6 & 45.5 & 2.3 & 3.2 \\
\hline B1 & 47.6 & 50.3 & 47.9 & 49.8 & 46.8 & 47.1 & 45.7 & 50.6 & 48.2 & 42.4 & 47.6 & 2.4 & 3.2 \\
\hline B2 & 42.9 & 41.7 & 44.1 & 42.8 & 46 & 44.9 & 46.5 & 44.2 & 46.9 & 45.4 & 44.5 & 1.7 & 2.4 \\
\hline B3 & 42 & 39.7 & 42.7 & 42.6 & 44 & 40.1 & 41.8 & 40.7 & 44.2 & 43.4 & 42.1 & 1.6 & 2.4 \\
\hline B4 & 42.7 & 41.9 & 42.2 & 41.1 & 41.4 & 40.7 & 40.3 & 43.9 & 39.5 & 41.3 & 41.5 & 1.3 & 1.9 \\
\hline B5 & 40.9 & 40.2 & 42.5 & 44.3 & 41 & 43.5 & 43.8 & 40.9 & 42.9 & 44.8 & 42.5 & 1.6 & 2.4 \\
\hline $\mathrm{C} 1$ & 45 & 52 & 48 & 50 & 44 & 45 & 41 & 49 & 45 & 41 & 46.0 & 3.7 & 5.1 \\
\hline $\mathrm{C} 2$ & 44 & 47 & 48 & 39 & 48 & 43 & 35 & 40 & 35 & 38 & 41.7 & 5.0 & 7.6 \\
\hline C3 & 34 & 37 & 40 & 37 & 40 & 33 & 45 & 42 & 46 & 32 & 38.6 & 4.9 & 8.0 \\
\hline $\mathrm{C} 4$ & 43 & 35 & 39 & 44 & 32 & 44 & 42 & 32 & 44 & 45 & 40.0 & 5.2 & 8.2 \\
\hline $\mathrm{C} 5$ & 39 & 41 & 37 & 36 & 31 & 34 & 36 & 39 & 37 & 45 & 37.5 & 3.8 & 6.5 \\
\hline D1 & 44.2 & 50.9 & 48.3 & 45.8 & 46.1 & 43.1 & 46.9 & 44.4 & 46 & 47.8 & 46.4 & 2.3 & 3.1 \\
\hline D2 & 43.7 & 39.8 & 41.3 & 42.4 & 41 & 41.1 & 44.1 & 41.5 & 41.2 & 41.7 & 41.8 & 1.3 & 2.0 \\
\hline D3 & 42.3 & 41.3 & 39.1 & 42.3 & 42.2 & 41.9 & 41.7 & 39.2 & 42.6 & 42.2 & 41.5 & 1.3 & 2.0 \\
\hline $\mathrm{D} 4$ & 42 & 39.5 & 40.1 & 40.7 & 39 & 37.5 & 41.5 & 40.5 & 40.1 & 37.5 & 39.8 & 1.5 & 2.4 \\
\hline D5 & 40 & 38.1 & 40.7 & 38.4 & 40.4 & 36.2 & 39.2 & 40.1 & 39.3 & 39.5 & 39.2 & 1.3 & 2.2 \\
\hline
\end{tabular}

the IAEA, within the terms and conditions of the Research Contract 20638 in the framework of the Coordinated Research Project (CRP) "Accelerator Driven Systems (ADS) Applications and Use of Low-Enriched Uranium in ADS (T33002)" within the Project "The Two-Zone Subcritical Systems with Fast and Thermal Neutron Spectra for Transmutation of Minor Actinides and Long-Lived Fission Products".

\section{Author contribution statement}

I. Romanenko prepared the samples of fiberconcrete reinforced by basalt-boron fiber and analyzed the obtained experimental results. M. Holiuk analyzed the obtained experimental results and prepared manuscript. P. Kutsyn analyzed the obtained experimental results and prepared manuscript. I. Kutsyna analyzed the obtained experimental results and prepared manuscript. G. Odinokin conducted the neutron experiment on $\mathrm{Pu}$-Be neutron source. A. Nosovskyi analyzed the obtained experimental results. V. Pastsuk prepared the samples of fiberconcrete reinforced by basalt-boron fiber and conducted the neutron experiment on $\mathrm{Pu}-\mathrm{Be}$ neutron source. M. Kiisk analyzed the obtained experimental results and prepared manuscript. A. Biland analyzed the obtained experimental results and prepared manuscript. Y. Chuvashov prepared the samples of basalt-boron fiber for neutron experiment. V. Gulik conducted the neutron experiment on $\mathrm{Pu}-\mathrm{Be}$ neutron source, analyzed the obtained experimental results and prepared manuscript.

\section{References}

1. Accelerator Driven Systems: Energy Generation and Transmutation of Nuclear Waste, Status Report, IAEA, Vienna, 1997

2. Use of Accelerator Based Neutron Sources, IAEA-TECDOC1153, IAEA, Vienna, 2000

3. C. Ipbuker, H. Nulk, V. Gulik, A. Biland, A.H. Tkaczyk, Radiation shielding properties of a novel cement-basalt mixture for nuclear energy applications, Nucl. Eng. Des. 284, $27(2015)$ 
4. V.P. Singh, N.M. Badiger, Investigation on radiation shielding parameters of ordinary, heavy and super heavy concretes, Nucl. Technol. Radiat. Prot. 29, 149 (2014)

5. V.P. Singh, N.M. Badiger, Gamma ray and neutron shielding properties of some alloy materials, Ann. Nucl. Energy 64, 301 (2014)

6. O. Icelli, Z. Yalcin, M. Okutan, R. Boncukcuoglu, Determination of photon energy absorption parameters for pellet waste, trommel sieve waste and original tincalconite, Ann. Nucl. Energy 47, 38 (2012)

7. B.S. Sidhu, A.S. Dhaliwal, K.S. Mann, K.S. Kahlon, Study of mass attenuation coefficients, effective atomic numbers and electron densities for some low Z compounds of dosimetry interest at $59.54 \mathrm{keV}$ incident photon energy, Ann. Nucl. Energy 42, 153 (2012)

8. N. Singh, K.J. Singh, K. Singh, H. Singh, Comparative study of lead borate and bismuth lead borate glass systems as gamma-radiation shielding materials, Nucl. Instrum. Methods Phys. Res. Sect. B 225, 305 (2004)

9. R. Sharma, V. Sharma, P.S. Singh, T. Singh, Effective atomic numbers for some calcium-strontium-borate glasses, Ann. Nucl. Energy 45, 144 (2012)

10. A.M. El-Khayatt, I. Akkurt, Photon interaction, energy absorption and neutron removal cross section of concrete including marble, Ann. Nucl. Energy 60, 8 (2013)

11. V.P. Singh, N.M. Badiger, Gamma photon exposure buildup factors for somespin ice compounds using
g-P fitting method, J. Nucl. Phys. Mater. Sci. Radiat. Appl. 2, 169 (2015)

12. M. Maslehuddin, A.A. Naqvi, M. Ibrahim, Z. Kalakada, Radiation shielding properties of concrete with electric arc furnace slag aggregates and steel shots, Ann. Nucl. Energy 53, $192(2013)$

13. E. Zorla, C. Ipbuker, A. Biland, M. Kiisk, S. Kovaljov, A.H. Tkaczyk, V. Gulik, Radiation shielding properties of high performance concrete reinforced with basalt fibers infused with natural and enriched boron, Nucl. Eng. Des. 313, 306 (2017)

14. I.M. Romanenko, M.I. Holiuk, A.V. Nosovsky, T.S. Vlasenko, V.I. Gulik, New composite material based on heavy concrete and basalt-boron fiber for neutron radiation shielding properties, Nucl. Radiat. Saf. 2, 19 (2019)

15. C. Ipbüker, E. Zorla, V. Gulik, S. Kovaljov, M. Kiisa, A. Biland, A.H. Tkaczyk, Optimization of basalt fiber in concrete composite for industrial application in Estonia, Fresenius Environ. Bull. 25, 355 (2016)

16. I.M. Romanenko, M.I. Holiuk, A.V. Nosovsky, T.S. Vlasenko, V.I. Gulik, Investigations of neutron radiation shielding properties for a new composite material based on heavy concrete and basalt fiber, Nucl. Radiat. Saf. 3, 42 (2018)

17. I.M. Romanenko, M.I. Holiuk, A.V. Nosovsky, V.I. Gulik, Investigation of Novel Composite Material Based on ExtraHeavy Concrete and Basalt Fiber for Gamma Radiation Protection Properties. Nucl. Radiat. Saf. 1, 52 (2018)

Cite this article as: Iryna Romanenko, Maryna Holiuk, Pavlo Kutsyn, Iryna Kutsyna, Hennadii Odynokin, Anatolii Nosovskyi, Vitalii Pastsuk, Madis Kiisk, Alex Biland, Yurii Chuvashov, Volodymyr Gulik, New composite material based on heavy concrete reinforced by basalt-boron fiber for radioactive waste management, EPJ Nuclear Sci. Technol. 5, 22 (2019) 